\title{
SIMBOLISMO \\ E INTERMIDIALIDADE
}

Andrẽ Soares Vieira*

Resumo: Ao romper com as noções realistas de representação e de ilusão referencial, afirmando a autonomia do universo formal da obra de arte, o movimento simbolista deu um dos primeiros passos para o desenvolvimento da obra que valoriza seus meios e materiais. Nessa perspectiva, o presente trabalho busca mapear alguns dos modos pelos quais a estética simbolista prepara o terreno para as futuras práticas da intermidialidade, sobretudo no que tange aos estudos das relações entre literatura e pintura.

Palavras-chave: Intermidialidade. Estética simbolista. Transposições de arte.

C

omo ponto de partida para as reflexões que aqui serão desenvolvidas, faço minhas algumas das ideias propostas por Walter Moser em seu ensaio sobre "As relações entre as artes: por uma arqueologia da intermidialidade", publicado na revista Aletria em 2006. Moser (2006, p. 42) justifica seu título como ângulo de abordagem do diálogo entre as artes para pensar a relação entre as mídias, sugerindo, assim, "que a longa tradição das relações entre as artes poderia fornecer os materiais para uma arqueologia da intermidialidade". De modo semelhante, endosso o argumento de Moser (2006, p. 43), segundo o qual

[...] a relação entre as artes, por implicação, comporta sempre, também, questões intermidiáticas, mesmo que estas não sejam explicitadas, considerando-se que toda arte inclui a "midialidade". A inversão desta afirmativa não é necessariamente verdadeira: a interação entre as midias pode se articular sem que as artes estejam aí implicadas. Transmitidas sempre por um alicerce midiático, a arte se distingue, entretanto, das mídias por algumas determinações - de natureza estética, por exemplo - que lhe impõem um campo mais reduzido. 
Uma vez que o presente ensaio se debruça sobre uma das categorias mais conhecidas e emblemáticas para o estudo das relações entre as artes, ou seja, entre pintura e literatura, artes da imagem e artes da palavra, tomo o conceito de intermidialidade, como Moser (2006), em um sentido mais amplo de "interação entre as mídias".

Para além da leitura de Moser (2006) calcada numa "arqueologia da intermidialidade", não há como pensarmos relações entre imagem e palavra sem recorrermos à perspectiva literária sobre a intermidialidade proposta por Irina Rajewsky (2012). Nesse sentido mais restrito de intermidialidade, a autora apresenta uma divisão tripartida da mesma: intermidialidade como transposição midiática, intermidialidade como combinação de mídias e intermidialidade como referências intermidiáticas. É nesta última subcategoria que algumas das relações entre a literatura e a pintura podem ser alocadas. Trata-se, segundo a autora, das referências, em um texto literário, a filmes, por exemplo, por meio de alusões ou evocações de procedimentos técnicos da linguagem cinematográfica. Ainda nessa categoria, incluir-se-iam as referências em filmes à pintura, em pinturas à fotografia, além de transposições de arte e écfrases (tradução de um texto/obra visual num texto escrito).

As referências intermidiáticas devem, então, ser compreendidas como estratégias de constituição de sentido que contribuem para a significação total do produto: este usa seus próprios meios, seja para se referir a uma obra individual específica produzida em outra mídia, [...] seja para se referir a um subsistema midiático específico, [...] ou a outra mídia como sistema (RAJEWSKY, 2012, p. 25).

Por definição, nessa terceira categoria, apenas uma mídia se apresenta em sua própria materialidade (a mídia de referência, em oposição à mídia a que se refere). Não se trata, portanto, da combinação das diferentes formas de articulação midiática, mas da tematização, evocação ou imitação de elementos e estruturas de outra mídia, percebida segundo seus meios específicos. Assim, referências picturais em um texto literário, seja através de transposições de arte ou de écfrases, evocariam procedimentos e técnicas da pintura, imitando quadros ao descrevê-los com o uso dos meios que são próprios à literatura: os signos verbais. Em suma, a pintura descrita não constitui uma pintura, mas faz uma alusão/referência/evocação ao quadro descrito por intermédio das palavras.

Em um sentido ainda mais restrito, proponho estabelecer uma relação entre artes e mídias em um contexto cronotópico específico: o movimento simbolista na França, na virada do século XIX para o XX.

É a partir do século XIX que as convergências entre literatura e pintura se tornam mais fecundas, pois se apoiam em correntes e escolas que irão estruturar a história da arte. Segundo Bergez (2011), os três grandes momentos representados pelo romantismo, o realismo e o simbolismo relançam a reflexão teórica e alimentam o pensamento estético. Após a distinção estabelecida por Lessing, separando categoricamente cada uma das artes em sua autonomia, o diálogo entre literatura e pintura parece condenado à extinção. As lições de Lessing, no entanto, serviram também para fomentar o desejo, sobretudo nos pintores, de reivindicar a especificidade de sua arte, buscando a autonomia do campo artístico em relação ao campo literário. Tal processo de autonomia estética 
Caminha, sem dúvida, ao lado do reconhecimento social e institucional do artista. Seu status não é mais questionado; a longa transição de "arte mecânica" à “arte liberal" está esquecida; os salões, os marchands particulares e as galerias [...] reconhecem seu valor inegável na vida cultural ${ }^{1}$ (BERGEZ, 2011, p. 24, tradução nossa).

Nesse sentido, os pintores oferecem aos escritores o modelo do artista puro que eles tentam inventar e impor; e a pintura pura, liberada da obrigação de servir a algo ou de simplesmente significar alguma coisa, opondo-se à tradição clássica e propondo uma arte "pura". Conforme observado por Bourdieu (1996), literatura e pintura reivindicam, assim, a institucionalização da anomia e a consequente liberdade na criação: busca por uma arte que dispense o motivo, o tema e tudo que possa evocar a intenção de reproduzir, de representar, de dizer. Os pintores abandonam o literário (a necessidade de representação), e os escritores se afastam do pictórico e do pitoresco em favor do literário e da literariedade. Aos poucos, cada campo percebe a necessidade de diferenciar as peculiaridades de suas expressões artísticas na busca pela forma que melhor convém a cada arte.

No entanto, é justamente nessa época que as trocas entre literatura e pintura se tornam mais frequentes e ricas, estabelecendo-se um diálogo, agora baseado no que Bergez (2011) chamou acertadamente de "proximidade distante", que irá alimentar não apenas a sedução, mas principalmente as rivalidades entre as duas artes.

O ápice desses debates entre artistas e escritores se dá, na França, durante as duas últimas décadas do século XIX. O germe que serviu para marcar o "começo do fim" das bases de sustentação da estética real-naturalista se encontra em Flaubert e Baudelaire na construção de alguns dos princípios que nortearão os pilares da modernidade. É nessa perspectiva que se alicerçam muitas das ideias finisseculares de decadentes e simbolistas. Tomando como referência maior o poema "Correspondances", de Baudelaire, a ideia de correspondência entre as artes assume novas feições para o simbolismo. Ao longo de todo o século XIX, a noção de pintores-escritores e de escritores-pintores se desenvolve de forma contundente. Diversos escritores praticam, não sem alguma constância, a crítica pictural e/ou a história da arte: de Stendhal a Laforgue, passando por Gautier, Baudelaire, Zola, Maupassant, Huysmans...

Literatura e pintura já não mais dialogam segundo o modelo clássico no qual a primeira se anexava à segunda nos planos teórico e estético. Agora, as relações são antes marcadas pelo confronto e fascinação mútuos:

A pintura é o "outro" da literatura, que se observa no espelho oferecido pela criação plástica. Baudelaire, por exemplo, logra melhor se fazer compreender, inclusive a si mesmo, ao falar de Constantin Guys, o "Pintor da vida moderna", e Delacroix esclarece de maneira magistral a prática e os princípios de sua arte em seu Diário² (BERGEZ, 2011, p. 25, tradução nossa).

\footnotetext{
No original: "[...] va sans nul doute de pair avec la reconnaissance sociale et institutionnelle de l'artiste. La question de son statut ne se pose plus; la longue transition du 'métier mécanique' à 'l'art libéral' est oubliée; les salons, marchands privés et galeries [...] lui reconnaissent un rôle irrécusable dans la vie culturelle".

2 No original: "La peinture est 'l'autre' de la littérature, qui s'observe dans le miroir que lui tend la création plastique. Baudelaire ne s'explique par exemple jamais mieux - et d'abord à lui-même - que lorsqu'il parle de Constantin Guys, le 'Peintre de la vie moderne', et Delacroix éclaire magistralement la pratique et les principes de son art dans son Journal".
} 
O século XIX é também o século dos manifestos, não apenas políticos, mas igualmente estéticos, nos quais a interação entre as artes se apresenta como exemplo de sustentação dos novos ideais defendidos. Em todos os movimentos literários, as demais artes são igualmente afetadas por um mesmo Zeitgeist, reproduzindo, através de seus próprios meios, a ideologia, a atmosfera, a estética e, de certo modo, o programa da época, em geral a partir de manifestos que tentam se demarcar das estéticas anteriores. Os manifestos, por sua vez, de forma geral, fazem apelo à necessidade de mudanças em todas as artes de seu tempo, o que faz deles um exemplo de produto intermidiático por excelência. Mesmo em se tratando de um manifesto literário, o apelo a outras artes e mídias é inevitável e decisivo para a garantia de seu sucesso. Ao longo do século XIX até meados do século XX, assistimos ao surgimento de uma série de manifestos estético-filosóficos que vão de Madame de Stael (1800) ao Refus Global quebequense em 1948, passando pelos prefácios a Cromwell, de Hugo, os prefácios a romances que acabaram por assumir feições de manifesto (Maupassant, Gautier, dentre outros), as vanguardas históricas das primeiras décadas do século XX (Surrealismo, Dadaísmo, Futurismo etc.), sem esquecer nossos manifestos antropofágicos e pau-brasil. Intermidiáticos por natureza, tais textos apoiam-se quase sempre na ideia de correlação e irmandade artísticas na defesa de seus pressupostos e diatribes.

A partir dos dois últimos decênios do século XIX, assiste-se, portanto, a uma espécie de retomada de alguns valores da sensibilidade romântica, olvidados desde o advento do real-naturalismo por volta de 1850. O simbolismo vem prolongar essa sensibilidade, voltando-se para o onírico, os estados feéricos, a força da imaginação e da sugestão na descrição de estados d'alma entre o místico, o profano e o nevrótico. O recurso ao símbolo, em um sentido amplo, permite a sugestão em lugar da descrição realista, apagando a realidade material, ou pelo menos tornando-a nebulosa e indefinida, em prol de uma presença/ausência vibrante. Para Mallarmé, tratava-se de querer transpor um fato da natureza em seu quase desaparecimento segundo o jogo da palavra.

O simbolismo representa igualmente, por seus contornos imprecisos, uma nebulosa no que respeita a sua fixação como escola ou movimento. Bergez (2011) argumenta que, malgrado a publicação de um manifesto simbolista por Jean Moréas em 1886, seus maiores autores estão situados à margem desta "escola" oficial: Verlaine e Mallarmé. Mutatis mutandis, os escritores tentam resgatar um "eu" perdido desde o romantismo, os mistérios da vida interior, antecipando as pesquisas de Freud sobre o inconsciente, em busca de "correspondências" da natureza e das artes. É o momento das "transposições de arte", textos nos quais melhor se configuram os ideais propagados pelo autor de As flores do mal e lugar ideal de uma criação em que cada arte se deixa inspirar pela outra, solicitando, para tanto, seus próprios meios. Eis o caráter propriamente intermidiático desse tipo de escritura híbrida, percebida em contos, poemas líricos e em prosa, romances e críticas de arte.

Na França, o simbolismo na pintura será representado, sobretudo, por Gustave Moreau e Odilon Redon. São, ao lado do belga Félicien Rops, os pintores mais admirados por escritores e críticos de arte simbolistas. Em comum, segundo Bergez (2011), os três artistas reivindicam uma função espiritual da arte por meio do predominio do universo onírico, da recusa ao ilusionismo (aperfeiçoado desde a Renascença, mas agora considerado esteticamente pobre), do retorno a uma forma presumida de simplicidade primitiva e da busca por um sentido superior. 
Romper com a representação figurativa do universo material, privilegiar a estilização e a busca de um sentido por meio de uma forma liberada da tradição, tais foram também as tentativas de poetas simbolistas, como Mallarmé e o primeiro Claudel. É quando a ressonância simbólica da palavra que importa, da mesma forma que a vibração espiritual da cor para o pintor ${ }^{3}$ (BERGEZ, 2011, p. 29, tradução nossa).

As transposições de arte em forma de poemas, contos e críticas foram abundantes, destacando-se as de Gautier, Huysmans, Lorrain e Laforgue. A picturalidade da escrita simbolista irá constituir sua principal marca distintiva, caracterizando a linguagem das transposições de arte. Em seu desejo em ver coexistindo literatura e pintura, os escritores estabelecem comparações entre as duas artes em suas respectivas mídias que ultrapassam o mero compartilhar de ideais estéticos e politicos com os artistas. Mais do que isso, importa lançar as bases de uma reflexão sobre a correspondência que é percebida entre os diferentes meios de expressão, e aqui me permito dizer uma "correspondência intermidiática" avant la lettre.

Graças a sua "originalidade absoluta", Redon seria digno de rivalizar com outros grandes poetas, pintores e músicos, pois ele pertence, como eles, a uma "classe de espírito" que "busca ardentemente na arte não as certezas científicas, mas as belezas desconhecidas, o estranhamento, a criação, o sonho dos novos meios de expressão, preciosos, fascinantes" 4 (HENNEQUIN, 1882 apud LUCBERT, 2005, p. 92, tradução nossa).

Em vários sentidos, o papel do crítico de arte simbolista aproximar-se-ia do papel do tradutor. Nesse viés, a transposição de um quadro assumiria a tarefa de uma tradução escrita, fazendo com que o leitor elaborasse mentalmente uma ideia das obras de arte, vistas ou não. Tradução e transposição de arte possuem, de fato, diversos traços em comum. Trata-se de pensar a noção desenvolvida por Walter Benjamin (2011) sobre o que ele chama de "tradução criativa" como forma de superar a inerente intraduzibilidade das obras. A essência da obra de arte, seu caráter inapreensivel, misterioso e poético, se mostraria acessível somente ao poeta. Ao refletir sobre questões que envolvem a traduzibilidade de composições da linguagem, Benjamin (2011, p. 103) afirma que a mesma

[...] deveria ser levada em conta, ainda que elas fossem intraduziveis para os homens. E não seriam elas, até certo ponto, de fato intraduziveis, se partirmos de um rigoroso conceito de tradução? - E é a partir de uma tal dissociação que se deve questionar se a tradução de determinadas composições de linguagem deve ou não ser exigida. Pois vale o princípio: se a tradução é uma forma, a traduzibilidade deve ser essencial a certas obras.

Assim, a traduzibilidade seria uma característica essencial de certas obras, nos originais das quais estaria contida uma determinada significação expres-

3 No original: "Rompre avec la représentation figurative de l'univers matériel, privilégier la stylisation et la receherche d'un sens par une forme libérée de la tradition, ce fut aussi la tentative des poètes symbolistes que furent Mallarmé et le premier Claudel. C'est alors la résonance symbolique du mot qui importe, au même titre que la vibrations spirituelle de la couleur pour le peintre"

4 No original: "Grâce à son 'originalité absolue', Redon serait digne de rivaliser avec les plus grands poètes, peintres et musiciens parce qu'il appartient, come eux, à une 'classe d'esprit' qui "recherche ardemment en art, non des certitudes scientifiques, mais des beautés inconnues, l'étrangeté, la création, le rêve des moyens d'expression neufs, précieux, saisissants" 
sa em sua traduzibilidade. Benjamin (2011, p. 104) adverte que, por melhor que seja, uma tradução jamais poderá significar algo para o original, "entretanto, graças à traduzibilidade do original, a tradução se encontra com ele em intima conexão".

Para muitos escritores e críticos de arte simbolistas, crítica e tradução estariam intimamente ligadas. Já é bastante conhecida a premissa de Huysmans sobre o tema. Segundo ele, o bom crítico de arte deveria ser capaz de traduzir os quadros de modo a torná-los visiveis aos leitores de seus textos. A única crítica que mereceria consideração deveria saber revelar as sensações sugeridas pelo pintor e, sobretudo, descrever o quadro de tal modo que aquele que lê sua tradução escrita consiga "ver" o quadro.

O estudo das relações entre tradução e transposição de arte a partir de alguns de seus traços comuns concorre para a caracterização dos processos de transferência entre pintura e linguagem. Ao elucidar os processos que subjazem à teoria da tradução, Roman Jakobson (1963) aponta, em seus Ensaios de linguistica geral, para a existência de três maneiras de interpretar um signo verbal. Trata-se da tradução intralingual, ou paráfrase, que tem lugar no seio da mesma língua; da tradução interlingual, quando um texto verbal é recriado em uma lingua diferente e, finalmente, da tradução intersemiótica, procedimento de trocas entre sistemas sígnicos distintos, "interpretação de signos verbais por meio de signos não verbais" (JAKOBSON, 1963, p. 78). Nessa direção, explica que a tradução intersemiótica seria produzida quando, por exemplo, se opera com transferências da linguagem para a pintura, a dança, a música ou o cinema: óperas transpostas de peças teatrais, filmes adaptados de romances, quadros inspirados em episódios bíblicos.

Percebe-se facilmente que Jakobson (1963) prevê essa operação em um único sentido, da linguagem verbal às outras artes e meios, esquecendo ou omitindo o percurso inverso da tradução, cujo conceito seria ampliado ao se aplicar a toda e qualquer transposição de um sistema de signos para outro, assim incluindo os movimentos da pintura em direção ao texto verbal.

É indubitável que o processo de adaptação, no sentido percebido por Jakobson como tradução intersemiótica tout court, representa um modo de relação recorrente entre o cinema e a literatura. No entanto, a terceira categoria de tradução, enquanto processo dinâmico de trocas e de transferências entre sistemas de signos, linguísticos ou não, em um sentido mais amplo, não deveria prescindir da análise das interpretações verbais de práticas não verbais.

Os procedimentos de tradução, adaptação e transposição de obras de arte constituídas por signos não verbais - picturais, musicais etc. - para o texto literário não são novos, mas merecerão uma atenção especial, sobretudo ao final do século XIX, quando a pintura passa a ser o objeto privilegiado de descrições por parte de muitos escritores simbolistas. Diversas pesquisas apontaram igualmente para a transposição de elementos próprios à linguagem musical em romances e poemas.

Ainda para Jakobson (1963), todas as traduções são, por natureza e intrinsicamente, irrealizáveis. Tal dogma, no entanto, não impediu o trabalho dos tradutores: a tradução é impossivel, mas é preciso traduzir como prova do contrário. Nessa situação contraditória, afirma-se a distância entre a teoria - a retórica da intraduzibilidade - e a prática - o exercício da tradução. Lucbert (2005, p. 202, tradução nossa) sublinha que a retórica da intraduzibilidade 
[...] repousa sobre um postulado ao mesmo tempo falso e verdadeiro: seria antinômico afirmar não ser possível traduzir quando tal prática efetivamente ocorre, porém justifica-se o pensamento segundo o qual a interpretação jamais restitui perfeitamente seu objeto. A obra original contém uma parte inapreensível, algo de essencial e de irredutivel que resiste a toda translação ${ }^{5}$.

Em se tratando do intérprete de uma obra de arte, o problema se agrava, obrigando constantemente o escritor/crítico/tradutor a se justificar ao discorrer sobre a pintura. Seguindo o pressuposto de Paul Valéry, segundo o qual todas as artes vivem de palavras e toda obra exige que se lhe responda, Lucbert (2005, p. 203, tradução nossa) argumenta que a tradução da pintura em signos verbais responderia à "necessidade de comunicar a experiência da pintura por intermédio da linguagem"6.

O caráter "incomunicável" da pintura seria, então, corroborado pela ideia de que não se pode dizer totalmente aquilo que se vê. Tendo em vista essa premissa, a aproximação entre pintura e linguagem estaria circunscrita à ordem da metáfora. A tentativa de resolução de tal impasse, que envolve questões complexas como a descrição de um artefato plástico que "diz" apenas aquilo que é mostrado, mas, ao mesmo, tempo possui algo de inapreensivel que ultrapassa a imagem representada, equivaleria à dificuldade em se traduzir a poesia para outra língua, no sentido já citado por Jakobson (1963). Para os simbolistas, essa era uma questão vital e a solução encontrada partiria justamente desse caráter intraduzivel da pintura. A ideia de tradução dá espaço, assim, àquela de transposição criativa, a única forma de (re)criação daquilo que Benjamin (2011) denominou realidade inapreensivel, misteriosa e poética, comum à poesia e à pintura, e somente acessivel ao poeta.

A transposição de arte, segundo Lucbert (2005), englobaria as ideias de deslocamento, de transformação e de adaptação. A ideia de adaptação enquanto textualização da pintura ou de uma colocação em texto da obra pictural apresenta-se como a que melhor responderia à inserção da escrita pictural em uma perspectiva intermidiática. Semelhante ao processo de adaptação de um texto dramático, de uma peça teatral para o universo cênico do palco, a transposição de arte, conforme percebe Lucbert (2005), adapta a materialidade pictural do quadro à realidade concreta do texto. Nesse processo de "textualização" da imagem, através do qual a transposição de arte transpõe para o texto uma obra produzida em outra mídia, afirma-se o caráter intermidiático da escrita simbolista. A substância pictural do quadro é metamorfoseada em substância escrita da obra literária, pois a imagem se torna texto.

Avatar da écfrase, a transposição de arte não pretende, no entanto, apresentar uma poética submetida à pintura, fundada sobre a descrição de uma imagem. Desde o Gaspard de la Nuit, de Alouysius Bertrand, passando por Baudelaire e chegando até Apollinaire, não se trata da mera evocação de obras precisas: os poetas mantêm-se no "[...] domínio do efeito subjetivo, da atmosfera, das conotações: território comum ao pintor e ao poeta; não há transposição de formas

5 No original: "[...] repose sur un postulat à la fois faux et vrai: il est antinomique d'affirmer qu'on ne peut traduire alors que l'on est en train de le faire, mais il est justifié de penser que l'interprétation ne rend jamais parfaitement son objet. L'oeuvre originale contient une part d'insaisissable, quelque chose d'essentiel et d'irréductible qui résiste à toute translation".

6 No original: "[...] la nécessité de communiquer l'expérience de la peinture par le moyen du langage". 
ou de técnicas, mas antes analogia da visão"7 (GLIKSOHN, 1989, p. 257, tradução nossa). Bertrand, Baudelaire, Huysmans e Lorrain, dentre outros que fizeram da transposição de arte um recurso formal de inserção do imaginário poético da pintura em seus romances, poemas e críticas de arte, apelaram aos elementos dos quais não dispõe o pintor: "[...] diálogos, metamorfoses fantásticas, efeitos de ironia, musicalidade [...]"8 (GLIKSOHN, 1989, p. 257, tradução nossa), além dos ritmos e demais convenções próprias à linguagem poética.

Em alguns casos extremos, não se trata sequer da simples evocação de uma imagem, tampouco de reproduzi-la, imitando suas técnicas e temas com os meios da poesia. É o exemplo de Bertrand com suas Fantasias à maneira de Callot, subtítulo ou menção genérica de seu Gaspard de la Nuit, mais interessado numa espécie de desenvolvimento da transposição. Seus textos, conforme percebeu Gliksohn (1989), dialogam com uma certa sabedoria serena que emana das obras de Callot.

Segundo Louvel (2012, p. 47), "o pictural seria o surgimento de uma referência às artes visuais em um texto literário, sob formas mais ou menos explícitas, com valor de citação, produzindo um efeito de metapicturalidade textual". No caso de uma descrição pictural, o leitor deverá se esforçar em representar para si mesmo a imagem descrita que, em seu caso mais simples, é um quadro "real".

Em seguida, com a imagem pictural em mente, deverá compará-la à personagem [...] e deduzir o valor proléptico, simbólico etc. Em síntese, trata-se de identificar o que está em jogo na inserção da imagem no texto. Donde se pode concluir que a relação ut pictura poesis transmitiria verdades mais figurativas que literais (LOUVEL, 2006, p. 193).

Vista por Leo Hoek (2006) como um dos três tipos de relações físicas entre o texto e a imagem, a escrita pictórica das transposições de arte partiria do princípio de primazia da imagem, do ponto de vista da produção. Na classificação pragmática do que Hoek (2006, p. 171) denomina transposição intersemiótica, uma vez que evoca relações e transferências entre sistemas sígnicos diferentes, "a submissão do texto - ao menos presumida - à imagem constitui o critério para se falar em primazia; [...] trata-se então de uma relação orientada em que o texto pressupõe a imagem".

Nesse viés, a transposição de imagens pela escrita servir-se-ia dos mesmos temas que a arte com o intuito de imitá-la e até mesmo com ela rivalizar, pois "a poesia se esforça em exprimir verbalmente as mesmas emoções provocadas pela obra de arte" (HOEK, 2006, p. 172). A obra verbal assume, assim, as seguintes funções: de comentário de uma imagem - o autor do comentário se coloca a ser viço da obra de arte, para analisá-la, explicá-la, situá-la em seu contexto; de transposição (poetização) de uma imagem pela escrita, écfrase, transposição de arte: a poesia transposicional se esforça em exprimir verbalmente as mesmas emoções provocadas pela obra de arte e, finalmente, relato de uma imagem, com a inserção da descrição de uma obra de arte em um texto narrativo. É o caso do romance de arte, em que o protagonista é pintor, músico ou escultor, e no qual o autor introduz descrições de obras de arte, reais ou imaginárias.

\footnotetext{
7 No original: "[...] domaine de l'éffet subjectif, de l'atmosphère, des connotations: territoire commun au peintre et au poète; il n'y a pas de transposition des formes ou des techniques mais simple analogie de la vision".

8 No original: "[...] dialogues, métamorphoses fantastiques, effets d'ironie, musicalité [...]".
} 
Muitas vezes, o objetivo ecfrástico é esquecido, e a poesia pictural acaba sendo um pretexto para uma poesia autônoma. A descrição de uma obra de arte no interior de um texto teria uma função narrativa. Conforme o efeito visado, teremos, segundo Hoek (2006), quatro funções diferentes, retomadas de Sophie Bertho (1990). A primeira é chamada de função psicológica: caracterização das personagens a partir de suas reações à arte. Exemplo: a influência das artes no caráter de Dorian Gray, a relação de Des Esseintes com as artes em Às avessas:

Após ter-se desinteressado da existência contemporânea, havia decidido não introduzir em sua célula larvas de repugnâncias ou pesares; quisera, por isso, uma pintura sutil, extravagante, mergulhada num antigo sonho, numa corrupção antiga, longe de nossos costumes, de nossos dias [...] obras sugestivas que o transportassem a um mundo desconhecido, desvendando-lhe os rastros de novas conjecturas, sacudindo-lhe o sistema nervoso com histerias eruditas, pesadelos complicados, visões lânguidas e atrozes. Existia, entre todos, um artista cujo talento o arrebatava em longos transportes, Gustave Moreau (HUYSMANS, 1987, p. 83).

A segunda função da descrição de uma obra de arte no interior de um texto apontada por Hoek (2006) seria de ordem retórica e consistiria em produzir o efeito da arte sobre uma das personagens. Por sua vez, a função estrutural projetaria a estrutura pictural sobre a obra literária, o tema pictural sendo apresentado como uma obra dentro da obra, espécie de mise en abyme do tema diegético. Finalmente, a função ontológica: quando a obra de arte simboliza o próprio sentido da obra literária.

Para os simbolistas, as transposições de arte viriam acrescentar algo ao modelo, ao texto-fonte, ao transfigurarem o quadro por meio da linguagem, assim como os pintores sublimariam a natureza por intermédio dos meios plásticos. Para Françoise Lucbert (2005), é aqui que podemos melhor apreender a face criadora na escritura simbolista da pintura. Ao acrescentar alguma coisa ao quadro, a transposição o embeleza, idealizando-o e poetizando-o, o que permite e autoriza uma certa liberdade e até mesmo uma extrapolação em sua maneira de interpretar a obra de arte plástica. Assim como Hoek, Lucbert destaca que a obra de arte prima sobre o texto no momento de produção e, portanto, serve de pré-texto a um tipo de atividade profundamente literária. Emulando o trabalho do pintor, o escritor simbolista busca, com sua prosa poética, não apenas superar, mas sobretudo rivalizar com os quadros.

Finalmente, para entendermos a escrita pictórica do simbolismo como processo intermidiático, convém pensarmos a descrição pictural, como o faz Louvel (2012, p. 62), ou seja, como sistema de equivalências, ao problematizar, como toda descrição, os saberes que ali operam:

A obra de arte no texto constitui um dos lugares mais privilegiados da codificação de saberes, donde a abundância de definições, de referências à tradição, de glosas, de interpretações, de julgamentos estéticos. Sua função seria dar ao texto um verniz erudito, um alcance didático, até mesmo estético, a fortiori quando ela é apresentada desde o início.

É ao longo do último decênio do século XIX que o movimento simbolista conhece seu apogeu e desenvolvimento. É igualmente sua idade do ouro, quando diversas artes são abrangidas. De resto, poucas épocas viram tal colaboração 
entre as artes. Jean-Nicolas Illouz (2014, p. 60, tradução nossa) cita algumas dessas colaborações:

Os pintores Maurice Denis e Carlos Schwabe ilustram partições de Debussy; outros ornam livros de poetas; Pelléas e Mélisande (1892), de Maeterlinck, torna-se uma ópera de Debussy em 1902; Debussy, Ravel, Fauré ou Chauson transformam em música poemas de Verlaine ou de Mallarmé, a ponto de a época simbolista despontar como um momento excepcionalmente fecundo na história da melodia frances $a^{9}$.

O simbolismo, como sabemos, destaca-se das demais tendências estéticas justamente por apelar constantemente a esse sistema de equivalências, de correspondências, como diria Baudelaire, entre saberes, artes e técnicas. Para dar conta das diversas artes envolvidas, faz-se necessária a atualização dos meios, das mídias em que cada arte é apresentada. Mais do que em qualquer outra escola ou movimento, o sistema simbolista de equivalências entre as artes e mídias sempre constituiu a base programática, o meio e a justificativa para o advento de uma estética avessa ao positivismo real-naturalista. Além disso, preparou o terreno para as futuras vanguardas históricas do século $\mathrm{XX}$, sobretudo para o Surrealismo que muito deve aos experimentos intermidiáticos avant la lettre dos simbolistas.

Desde suas origens pintura e escrita estiveram ligadas pela representação gráfica, pelo desenho em seu traço, mas o gesto escritural é fruto de uma voz, a escrita fonética representando a phoné, dando forma à primeira representação mimética. O que ouvimos, a voz, também está ligada ao desenho (o contorno), aquilo que vemos. Triunfo da sinestesia (LOUVEL, 2012, p. 65).

Ainda segundo Louvel, o entrelaçamento do visual e da voz, do que é visivel e do que é legivel, produziria o ritmo, responsável pela absorção da aparente tensão entre os dois sistemas semióticos. Através do ritmo, do texto e das imagens são tecidos, produzidos concomitantemente pela descrição pictural (voz e visão). Voz e visual entrelaçam-se oriundos de uma mesma tessitura. Tais noções apenas corroboram a essência mesma da estética simbolista: sinestésica, sugestiva, onírica e, sobretudo, direcionada, por sua própria natureza, à diluição das fronteiras entre os meios de comunicá-las.

Tanto em pintura quanto em literatura, impõe-se a necessidade comum de rejeitar a fidelidade à representação de uma realidade exterior. No caso da pintura, trata-se da rejeição categórica não apenas à pintura realista e acadêmica, como também à escola impressionista. Defendendo a noção segundo a qual a arte é uma abstração e que, portanto, deve primar pela sugestão e não pelo caráter descritivo da ilusão referencial, os artistas simbolistas consideram a estética impressionista, fiel às impressões, como uma forma apenas mais sofisticada do Realismo. O quadro de Gauguin La vision du sermon ou La Lutte de Jacob avec l'ange (1888), além de adquirir um valor de manifesto dos novos ideais simbolistas, ilustra com perfeição o que Illouz (2014, p. 61, tradução nossa) qualifica como "uma nova organização do espaço pictural, fundada não sobre a

9 No original: "Les peintres Maurice Denis et Carlos Schwabe illustrent des partitions de Debussy; d'autres ornent des livres de poètes; Pelléas et Mélisande (1892), de Maeterlinck, devient un opéra de Debussy en 1902; Debussy, Ravel, Fauré ou Chausson mettent en musique des poèmes de Verlaine ou de Mallarmé, au point que l'époque symboliste apparait comme un moment exceptionnellement fécond dans l'histoire de la mélodie française". 
fidelidade da representação [...] mas sobre o agenciamento harmônico dos constituintes internos do quadro que são as superficies e as cores"10.

Nesse contexto, mesmo a reprodução mimética "espiritualizada" da realidade como feita pelos impressionistas representaria a morte da ideia. Para os simbolistas, a realidade somente pode ser retratada como signo e apenas o homem de gênio seria capaz de "decifrar" a visão interior dos objetos, sua ideia ou abstração. Como podemos perceber, ao instaurar um laço necessário entre a ideia e a forma, a estética simbolista privilegia e acentua o papel adquirido pelas formas e meios para sua reprodução. Trata-se, com efeito, de uma valorização do espaço da pintura enquanto tal. Antes de ser a representação de qualquer coisa, um quadro nada mais é senão uma superfície plana coberta de um agenciamento de volumes e cores.

A renovação simbolista reside, portanto, no deslocamento do sujeito representado à representação como tal, mas sobretudo "[...] na afirmação da primazia da organização interna da obra sobre a mera ilusão referencial"11, conforme observa Illouz (2014, p. 64, tradução nossa). Tais propósitos serão endossados por grande parte de escritores, poetas e críticos de arte, coetâneos ou epígonos do movimento simbolista: é o caso das escritas de Mallarmé e de Valéry, entre outros. Ao defenderem o valor dos espaços picturais e poéticos, dos lugares da pintura e da literatura, privilegiando os agenciamentos das cores e das palavras, na tela ou na página, os simbolistas introduzem o debate sobre os meios, as mídias em que suas artes se concretizam. Literatura e pintura passam a desenvolver novos tipos de relações, não apenas em seus diálogos e correspondências, mas igualmente no reconhecimento da importância do quadro e da página, dos materiais de que dispõe pintores e escritores para sugerir ideias em estado puro. Afirmando as correspondências e relações entre as artes e suas mídias, o simbolismo abre caminho para as futuras pesquisas sobre os estudos interartes e intermidiáticos da contemporaneidade.

\section{SYMBOLISM AND INTERMEDIALITY}

Abstract: By breaking with the realist notions of representation and referential illusion, affirming the autonomy of the formal universe of the work of art, the symbolist movement gives one of the first steps towards the development of the work that values its means and materials. In this perspective, this paper focuses on some of the ways in which the symbolist aesthetic prepares the ground for the future practices of intermediality, especially in what concerns the studies of the relations between literature and painting.

Keywords: Intermediality. Symbolist aesthetics. Art transpositions.

\section{REFERÊNCIAS}

BENJAMIN, W. Escritos sobre mito e linguagem. Tradução Susana K. Lages. São Paulo: Editora 34, Duas cidades, 2011.

\footnotetext{
10 No original: "Une nouvelle organisation de l'espace pictural, fondée non sur la fidelité de la représentation [...] mais sur l'agencement harmonique des constituants internes du tableau que sont les surfaces et les couleurs".

11 No original: "[...] dans cette affirmation de la primauté de l'organisation interne de l'oeuvre sur la simple illusion référentielle".
} 
BERGEZ, D. Littérature et peinture. Paris: Armand Colin, 2011.

BOURDIEU, P. As regras da arte. Tradução Maria Lucia Machado. São Paulo: Companhia das Letras, 1996.

GLIKSOHN, J.-M. Littératures et arts. In: BRUNEL, P.; CHEVREL, Y. (Direc.). Précis de littérature comparée. Paris: PUF, 1989.

HOEK, L. A transposição intersemiótica: por uma classificação pragmática. In: ARBEX, M. (Org.). Poéticas do visivel: ensaios sobre a escrita e a imagem. Belo Horizonte: PósLit/Fale/UFMG, 2006.

HUYSMANS, J.-K. Às avessas. Tradução José Paulo Paes. São Paulo: Companhia das Letras, 1987.

ILLOUZ, J.-N. Le Symbolisme. Paris: Le livre de poche, 2014.

JAKOBSON, R. Essais de linguistique générale. Paris: Minuit, 1963.

LOUVEL, L. A descrição pictural: por uma poética do iconotexto. Tradução Luiz Claudio de Oliveira. In: ARBEX, M. (Org.). Poéticas do visivel: ensaios sobre a escrita e a imagem. Belo Horizonte: PósLit/Fale/UFMG, 2006.

LOUVEL, L. Nuanças do pictural. Tradução Marcia Arbex. In: DINIZ, T. F. N. (Org.). Intermidialidade e estudos interartes. Belo Horizonte: Editora UFMG, 2012.

LUCBERT, F. Entre le voir et le dire. Rennes: PUR, 2005.

MOSER, W. As relações entre as artes: por uma arqueologia da intermidialidade. Aletria, Belo Horizonte, v. 6, n. 14, p. 42-65, jul./dez. 2006.

RAJEWSKY, I. O. Intermidialidade, intertextualidade e "remediação": uma perspectiva literária sobre a intermidialidade. In: DINIZ, T. F. N. (Org.). Intermidialidade e estudos interartes. Belo Horizonte: Editora UFMG, 2012.

Recebido em dezembro de 2016.

Aprovado em janeiro de 2017. 